Article

\title{
Stimuli Responsive Materials Supported by Orthogonal Hydrogen and Halogen Bonding or I...Alkene Interaction
}

\author{
Pierre Frangville ${ }^{1}$, Shiv Kumar ${ }^{1} \mathbb{D}$, Michel Gelbcke ${ }^{1}$, Kristof Van Hecke ${ }^{2} \mathbb{D}$ and Franck Meyer ${ }^{1, *} \mathbb{C}$ \\ 1 Microbiology, Bioorganic and Macromolecular Chemistry Unit, Faculty of Pharmacy, Boulevard du Triomphe, \\ 1050 Brussels, Belgium; Pierre.frangville@ulb.be (P.F.); shiv.kumar@ulb.be (S.K.); \\ Michel.Gelbcke@ulb.be (M.G.) \\ 2 XStruct, Department of Chemistry, Ghent University, Krijgslaan 281-S3, 9000 Ghent, Belgium; \\ kristof.vanhecke@ugent.be \\ * Correspondence: Franck.meyer@ulb.be; Tel.: +32-(0)2-650-51-96
}

check for updates

Citation: Frangville, P.; Kumar, S.; Gelbcke, M.; Van Hecke, K.; Meyer, F. Stimuli Responsive Materials Supported by Orthogonal Hydrogen and Halogen Bonding or I...Alkene Interaction. Molecules 2021, 26, 7586. https://doi.org/10.3390/ molecules 26247586

Academic Editors: Ryan Groeneman, Eric Reinheimer and Axel Klein

Received: 26 October 2021

Accepted: 10 December 2021

Published: 14 December 2021

Publisher's Note: MDPI stays neutral with regard to jurisdictional claims in published maps and institutional affiliations.

Copyright: (c) 2021 by the authors. Licensee MDPI, Basel, Switzerland. This article is an open access article distributed under the terms and conditions of the Creative Commons Attribution (CC BY) license (https:// creativecommons.org/licenses/by/ $4.0 /)$.

\begin{abstract}
Smart materials represent an elegant class of (macro)-molecules endowed with the ability to react to chemical/physical changes in the environment. Herein, we prepared new photo responsive azobenzenes possessing halogen bond donor groups. The X-ray structures of two molecules highlight supramolecular organizations governed by unusual noncovalent bonds. In azo dye I-azo- $\mathrm{NO}_{2}$, the nitro group is engaged in orthogonal $\mathrm{H} \cdots \mathrm{O} \cdots \mathrm{I}$ halogen and hydrogen bonding, linking the units in parallel undulating chains. As far as compound I-azo-NH-MMA is concerned, a noncentrosymmetric pattern is formed due to a very rare $\mathrm{I} \cdots \pi$ interaction involving the alkene group supplemented by hydrogen bonds. The Cambridge Structural Database contains only four structures showing the same $\mathrm{I} \cdots \mathrm{CH}_{2}=\mathrm{C}$ contact. For all compounds, an ${ }^{19} \mathrm{~F}-\mathrm{NMR}$ spectroscopic analysis confirms the formation of halogen bonds in solution through a recognition process with chloride anion, and the reversible photo-responsiveness is demonstrated upon exposing a solution to UV light irradiation. Finally, the intermediate I-azo- $\mathrm{NH}_{2}$ also shows a pronounced color change due to $\mathrm{pH}$ variation. These azobenzenes are thereby attractive building blocks to design future multi-stimuli responsive materials for highly functional devices.
\end{abstract}

Keywords: halogen bonding; azobenzene; $\mathrm{pH}$ sensitive; stimuli responsive; orthogonal interaction

\section{Introduction}

Stimuli responsive materials are fascinating compounds with the ability to translate a stimulus into a change of physical/chemical properties at the nano/macro-scale [1]. The careful design of smart systems has opened new perspectives for the conception of next generation of highly functional materials in various domains $[2,3]$. The chemical toolbox is thereby comprised of a large array of molecular groups that can be finely modified/adapted for the creation of stimuli responsive drug delivery systems, sensors, smart surfaces or purification devices [4,5]. Typically, the responsivity of these compounds is triggered by varied stimuli such as a change of temperature [6], pH [7], magnetic environment [8], redox condition [9], photo-irradiation [10] and many others. In the arena of smart systems, photo-responsive materials have a photo switching ability in a reversible or irreversible fashion that consists in chemical bond breaking/formation or a conformational change upon irradiation [11]. Among these switchable compounds, azobenzenes represent a very appealing class of molecules that can reversibly isomerize from trans to cis form and vice versa [12]. An interesting feature lies in the fact that several synthetic pathways have been developed to prepare symmetric or asymmetric azobenzene derivatives [13]. Moreover, structural modifications of the azobenzene core allow for a fine tuning/shifting of absorbance in the red region and even the near-infrared, whereas shorter wavelength UV radiation is generally used to induce the isomerization [14,15]. 
In the last two decades, the halogen bonds $(\mathrm{XB})$, i.e., the interactions involving a halogen as acceptor of electronic density, have become a huge point of interest in the scientific community $[16,17]$. Although similar in many aspects to hydrogen bonds, XB have demonstrated some specificities in synthetic chemistry [18], biological and materials sciences $[19,20]$. As far as the applications of azobenzene-based XB donors are concerned, the light induced surface patterning was achieved using asymmetric self-complementary azo dyes linked to poly(4-vinylpyridine) through $\mathrm{N} \cdots \mathrm{I}$ halogen bonds [21,22]. Other works have reported the formation of photomechanical azo crystals and a gelator capable of undergoing a gel-to-sol transition upon green light irradiation, involving symmetric XB compounds $[23,24]$. However, only a handful of instances has studied the design and application of such XB molecules, which are usually prepared in moderate yields [25]. Considering this, we decided to develop a straightforward access to photo responsive compounds with XB donor ability. In contrast to azo dyes already described in the literature, these compounds aim at being appended to a substrate such as a polymer which has never been described so far [26]. Recently, we have reported the preparation of stimuli-responsive polymers having the capability to react to a change of $\mathrm{pH}$, magnetic field and UV-light irradiation [27]. In the same way, and as a preliminary result in the formation of new XBbased smart materials, our endeavors herein are devoted to the synthesis, $X$-ray structure analysis and determination of physico-chemical properties of new azo dyes endowed with $\mathrm{XB}$ donor capability, light responsiveness and even $\mathrm{pH}$ sensitivity for a synthetic intermediate.

\section{Results \& Discussion}

\subsection{Synthesis of Halogen Bonded Azobenzenes}

The preparation of halogen bonded azobenzenes was performed through a multistep synthesis (Scheme 1).

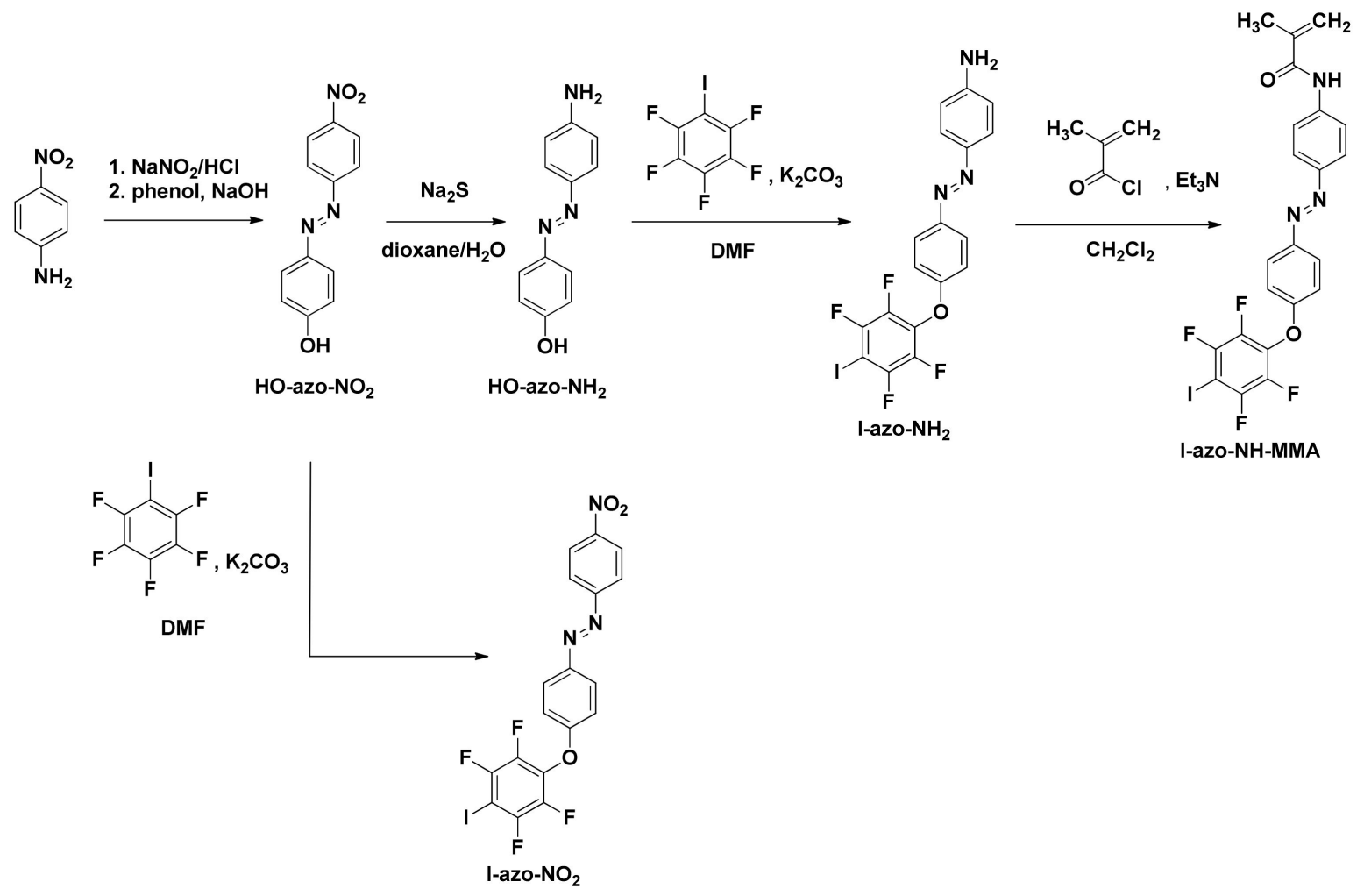

Scheme 1. Synthesis of halogen bonded azobenzene derivatives.

First of all, the azobenzene core, namely 4-((4-nitrophenyl)diazenyl)phenol (HO-azo$\mathrm{NO}_{2}$ ), was obtained in $96 \%$ yield by diazotization of 4-nitroaniline with sodium nitrite in 
the presence of hydrochloric acid, followed by a coupling reaction with phenol in alkaline conditions, according to a procedure already described in the literature [28]. Subsequently, the incorporation of a halogen bond donor group was achieved by nucleophilic replacement of fluorine of pentafluoroiodobenzene using $\mathrm{HO}-\mathrm{azo}-\mathrm{NO}_{2}$ and potassium carbonate in dimethylformamide (DMF) at $50{ }^{\circ} \mathrm{C}$. As such, the resulting I-azo- $\mathrm{NO}_{2}$ was isolated in $95 \%$ yield. In order to prepare a polymerizable azobenzene, $\mathrm{HO}-\mathrm{azo}-\mathrm{NO}_{2}$ was first reduced with a large excess of sodium sulfide $\left(\mathrm{Na}_{2} \mathrm{~S}\right)$ in a dioxane/water mixture at $90{ }^{\circ} \mathrm{C}$ to give $\mathrm{HO}-\mathrm{azo}-\mathrm{NH}_{2}$ in $92 \%$ yield. Afterwards, the $\mathrm{XB}$ donor ring was introduced selectively on the hydroxy group to provide I-azo- $\mathrm{NH}_{2}$ in $91 \%$ yield. Finally, I-azo-NH-MMA was obtained by the reaction of methacryloyl chloride and $\mathrm{I}-\mathrm{azo}-\mathrm{NH}_{2}$ in the presence of triethylamine in dichloromethane at room temperature in 87\% yield (Figures S3-S7, Supplementary Materials).

\subsection{X-ray Structure Analysis of XB Azobenzenes}

Afterwards, the crystallographic structures of two azobenzene derivatives were studied as first evidence of their ability to form halogen bonds (Table 1).

Table 1. X-ray crystal data and refinement parameters for structures I-azo- $\mathrm{NO}_{2}$ and I-azo-NH-MMA.

\begin{tabular}{|c|c|c|}
\hline & $\mathrm{I}-\mathbf{a z o}-\mathrm{NO}_{2}$ & I-azo-NH-MMA \\
\hline Molecular formula & $\mathrm{C}_{18} \mathrm{H}_{8} \mathrm{~F}_{4} \mathrm{IN}_{3} \mathrm{O}_{3}$ & $\mathrm{C}_{22} \mathrm{H}_{14} \mathrm{~F}_{4} \mathrm{IN}_{3} \mathrm{O}_{2}$ \\
\hline Formula weight $\left(\mathrm{g} \cdot \mathrm{mol}^{-1}\right)$ & 517.17 & 555.26 \\
\hline$T(\mathrm{~K})$ & $100(2)$ & $100(2)$ \\
\hline Crystal system & triclinic & orthorhombic \\
\hline Space group & $P-1$ (No. 2) & $\operatorname{Pna}_{1}$ (No. 33) \\
\hline a $(\AA)$ & $5.65780(10)$ & $11.1393(2)$ \\
\hline $\mathrm{b}(\AA)$ & $9.9399(2)$ & $5.07170(10)$ \\
\hline$c(\AA)$ & $32.4971(4)$ & $36.6524(7)$ \\
\hline$\alpha\left(^{\circ}\right)$ & $91.9240(10)$ & 90 \\
\hline$\beta\left({ }^{\circ}\right)$ & $91.6640(10)$ & 90 \\
\hline$\gamma\left({ }^{\circ}\right)$ & $105.8040(10)$ & 90 \\
\hline $\mathrm{V}\left(\AA^{3}\right)$ & 1756.11(5) & $2070.68(7)$ \\
\hline Z & 4 & 4 \\
\hline$\rho_{\text {calc }}\left(\mathrm{g} \cdot \mathrm{cm}^{-3}\right)$ & 1.956 & 1.781 \\
\hline$\mu\left(\mathrm{mm}^{-1}\right)$ & 14.975 & 12.712 \\
\hline $\mathrm{F}(000)$ & 1000 & 1088 \\
\hline $2 \theta_{\max }\left({ }^{\circ}\right)$ & 147.59 & 147.34 \\
\hline Measured reflections & 61712 & 7384 \\
\hline Unique reflections & 6933 & 3466 \\
\hline Observed reflections $(I>2 \sigma(I))$ & 6250 & 3128 \\
\hline Parameters refined & 523 & 293 \\
\hline$R_{1}$ & 0.0250 & 0.0428 \\
\hline$w R_{2}$ & 0.0559 & 0.1109 \\
\hline$R_{1}$ (all data) & 0.0302 & 0.0485 \\
\hline$w R_{2}$ (all data) & 0.0584 & 0.1179 \\
\hline Goodness-of-fit (GOF) & 1.030 & 1.054 \\
\hline CCDC-entry & CCDC 2117642 & CCDC 2117643 \\
\hline
\end{tabular}

The slow evaporation of a dichloromethane solution of $\mathrm{I}-\mathrm{azo}-\mathrm{NO}_{2}$ provided materials with a needle-like crystal morphology suitable for X-ray diffraction analysis. I-azo- $\mathrm{NO}_{2}$ crystallized in the centro-symmetric space group $P-1$, with the asymmetric unit consisting of 
two complete azobenzene molecules. From a general point of view, the self-complementary azobenzenes develop undulating parallel chains running in opposite directions due to non-covalent bonds (Figure 1).

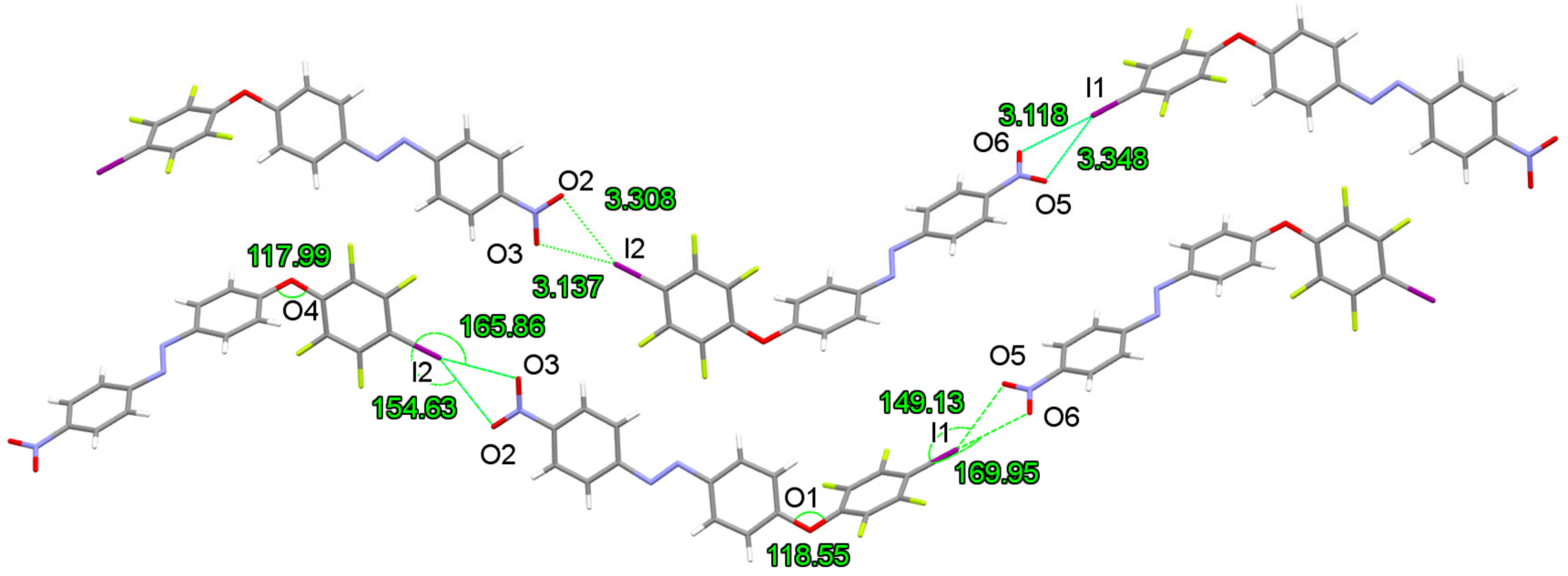

Figure 1. X-ray structure of $\mathrm{I}-\mathrm{azo}-\mathrm{NO}_{2}$ developing undulating parallel chains due to two $\mathrm{O} \cdots \mathrm{I}$ halogen bonds. Colors are

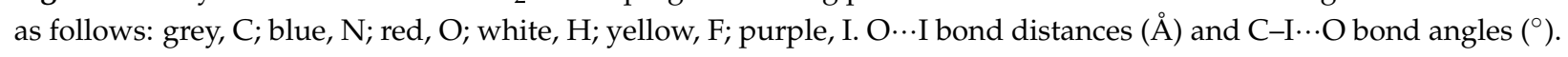

The wavy character of this arrangement is induced by oxygen atoms linking the tetrafluoroiodobenzene group to the azobenzene core, showing dihedral angles of $63.0(1)^{\circ}$ and $64.1(1)^{\circ}$ between the tetrafluoroiodobenzene and benzene rings, for both molecules, respectively. $\mathrm{NO}_{2} \cdots \mathrm{I}$ halogen bonds link the successive molecules into infinite chains and transfer the molecular information between almost equiplanar fluorinated and nitroaryl rings. In details, each iodine interacts with both oxygen atoms of the nitro group, but distances are slightly different, as defined in a Q-type interaction [29]. The I1 ... O5 and I2 $\cdots \mathrm{O} 2$ separations are 3.348(2) and 3.308(2) $\AA$, respectively, i.e., around 5\% shorter than the sum of van der Waals radii, whereas the I1 $\cdots \mathrm{O} 6$ and I $2 \cdots \mathrm{O} 3$ distances are slightly shorter ( $90 \%$ of the sum of van der Waals radii) (Table 2$)$ [30].

Table 2. Parameters of halogen and hydrogen bonds in $\mathrm{I}-\mathrm{azo}-\mathrm{NO}_{2}$.

\begin{tabular}{|c|c|c|c|c|}
\hline $\mathrm{d}(\mathrm{I} \cdots \mathrm{O}), \AA$ & $\mathrm{d}(\mathrm{I} \cdots \mathrm{O}) / \Sigma \mathrm{vdWr}, \%$ & $<(\mathrm{C}-\mathrm{I} \cdots \mathrm{O}),(\mathrm{H} \cdots \mathrm{O} \cdots \mathrm{I}),^{\circ}$ & $\mathrm{d}(\mathrm{H} \cdots \mathrm{O}), \AA$ & $\mathrm{d}(\mathrm{H} \cdots \mathrm{F}), \AA$ \\
\hline $3.348(2)(\mathrm{I} 1 \cdots \mathrm{O} 5)$ & $\sim 4.5$ & $149.13(\mathrm{C}-\mathrm{I} 1 \cdots \mathrm{O} 5)$ & $2.686(\mathrm{H} 35 \cdots \mathrm{O} 6)$ & $2.571(\mathrm{H} 29 \cdots \mathrm{F} 4)$ \\
\hline $3.118(2)(\mathrm{I} 1 \cdots \mathrm{O} 6)$ & $\sim 11$ & $169.95(\mathrm{C}-\mathrm{I} 1 \cdots \mathrm{O} 6)$ & $2.444(\mathrm{H} 15 \cdots \mathrm{O} 2)$ & $2.592(\mathrm{H} 32 \cdots \mathrm{F} 1)$ \\
\hline $3.308(2)(\mathrm{I} 2 \cdots \mathrm{O} 2)$ & $\sim 5.5$ & $154.63(\mathrm{C}-\mathrm{I} 2 \cdots \mathrm{O} 2)$ & & $2.636(\mathrm{H} 32 \cdots \mathrm{F} 2)$ \\
\hline \multirow[t]{5}{*}{$3.137(2)(\mathrm{I} 2 \cdots \mathrm{O} 3)$} & $\sim 10.5$ & $165.86(\mathrm{C}-\mathrm{I} 2 \cdots \mathrm{O} 3)$ & & $2.656(\mathrm{H} 17 \cdots \mathrm{F} 8)$ \\
\hline & & $100.54(\mathrm{H} 15 \cdots \mathrm{O} 2 \cdots \mathrm{I} 2)$ & & $2.574(\mathrm{H} 18 \cdots \mathrm{F} 8)$ \\
\hline & & $93.68(\mathrm{H} 35 \cdots \mathrm{O} 6 \cdots \mathrm{I} 1)$ & & $2.592(\mathrm{H} 11 \cdots \mathrm{F} 7)$ \\
\hline & & & & $2.570(\mathrm{H} 14 \cdots \mathrm{F} 5)$ \\
\hline & & & & $2.452(\mathrm{H} 9 \cdots \mathrm{F} 6)$ \\
\hline
\end{tabular}

In all cases, the $\mathrm{C}-\mathrm{I} \cdots \mathrm{O}$ angles are in the range of $\sim 149$ to $\sim 170^{\circ}$, which is consistent with halogen bonding parameters. Moreover, two adjacent units pointing in opposite directions are also connected through the nitro group by $\mathrm{H} 15 \cdots \mathrm{O} 2$ and $\mathrm{H} 35 \cdots \mathrm{O} 6$ hydrogen bonds of 2.444 and $2.686 \AA$, respectively. Therefore, O2 and O6 are simultaneously engaged in halogen and hydrogen bonds, the $\mathrm{H} 15 \cdots \mathrm{O} 2 \cdots \mathrm{I} 2$ and $\mathrm{H} 35 \cdots \mathrm{O} 6 \cdots \mathrm{I} 1$ angles being 100.5 and $\sim 93.7^{\circ}$, respectively (Figure 2 ). To date, few studies have reported an orthogonal relationship between these interactions [31]. Typically, such a supramolecular motif is observed in biological systems with a carbonyl group as electron donor [32]. Recently, a chloride anion was described as a hydrogen and halogen bond acceptor in a co-crystal composed of a 
pyrazolium salt and diiodotetrafluorobenzene [33]. It is interesting to note that the combination of these interactions also occurs in complexes of 4-nitrobenzamide/1,4-diiodobenzene and 1,4-dinitrobenzene/4-iodocinnamic acid [29,34]. Finally, the supramolecular scaffold is stabilized by a myriad of $\mathrm{H} \cdots \mathrm{F}$ contacts between head-to-tail adjacent molecules (Figure 2 and Table 2). The complementary bonded rings (i.e., tetrafluoroiodobenzene group and azobenzene core) belong to the same plane that generates a step-like organization.

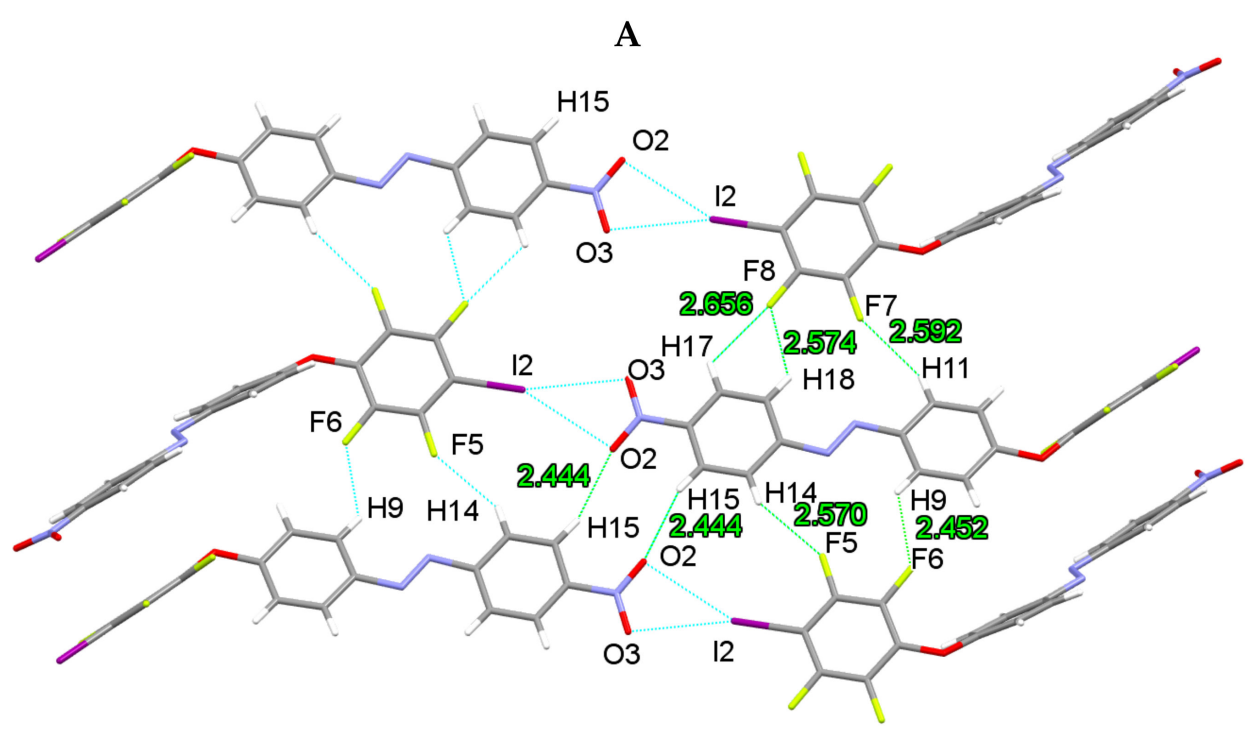

B

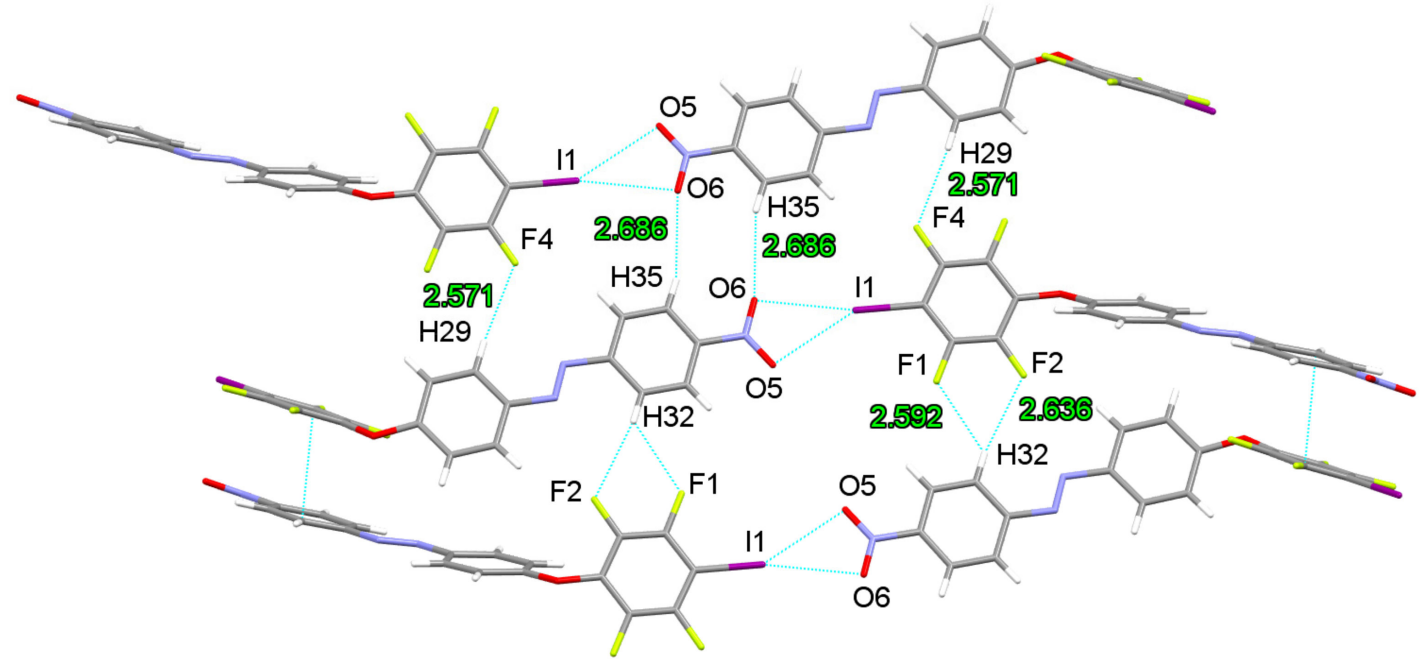

Figure 2. X-ray structure of $\mathrm{I}-\mathrm{azo}-\mathrm{NO}_{2}$ highlighting the $\mathrm{H} 15 \cdots \mathrm{O} 2 \cdots \mathrm{I} 2(\mathbf{A})$ and $\mathrm{H} 35 \cdots \mathrm{O} 6 \cdots \mathrm{I} 1$ (B) orthogonal hydrogen and halogen bonds.

Subsequently, the crystal formation of I-azo-NH-MMA was carried out using the aforementioned conditions. The compound crystallized in the non-centrosymmetric space group $P$ na2 1 , with one azobenzene molecule in the asymmetric unit. The X-ray structure of the supramolecular scaffold adopts a similar undulating linear arrangement provoked by the tetrahedral geometry of oxygen with sp3 hybridization (Figure 3). Here, successive units are linked due to $\mathrm{I} \cdots \pi$ halogen bonds involving the alkene functional group. The crystallographic parameters are in agreement with a halogen bond interaction, namely an

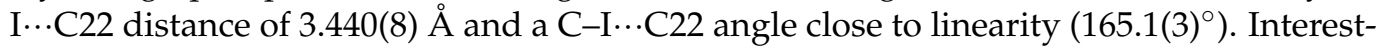

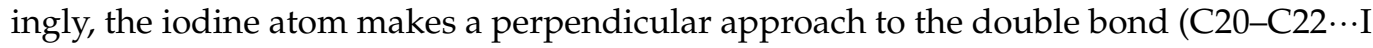
angle $\sim 90^{\circ}$ ), emphasizing the electron donation from the $\mathrm{p}$ orbital. 


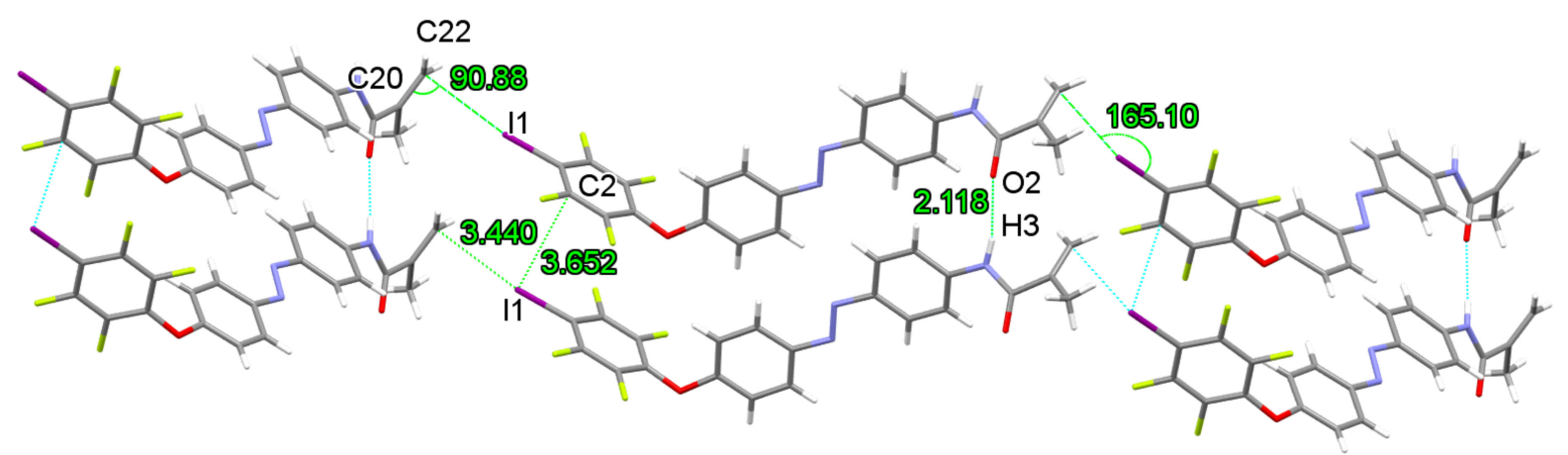

Figure 3. X-ray structure of I-azo-NH-MMA developing undulating parallel chains due to C $\cdots$ I halogen bonds.

This intriguing contact convinced us to make a Cambridge Structural Database (CSD version 5.42 updates, Sep 2021) analysis on the interaction between an iodine and a double bond $\left(\mathrm{I} \cdots \mathrm{CH}_{2}=\mathrm{C}, \mathrm{C} \cdots \mathrm{I}\right.$ distances between 3.0 and $4.0 \AA$ ). This survey reveals that only four molecules adopt the same structural motif, namely HOQKAC [35], HOTZOH [36], PEQVOZ [37] and USAJIK [38]. In these X-ray structures, the I $\cdots C$ interactions appear much weaker than in I-azo-NH-MMA, since the $\mathrm{I} \cdots \mathrm{CH}_{2}=\mathrm{C}$ distances are in the range of 3.526-3.692 Å (Figure S1, Supplementary Materials). In the XB-based azobenzene, a short distance exists between the negative equatorial region of the iodine atom and carbon atom of the electron deficient fluorinated group $(\mathrm{I} \cdots \mathrm{C} 2$ distance $=3.652 \AA)$. This phenomenon highlights the dual character of halogen atoms, and more particularly of iodine, that can behave both as electron donor and acceptor $[39,40]$. Finally, the supramolecular architecture features $\mathrm{N}-\mathrm{H} \cdots \mathrm{O}$ hydrogen bonds $(\mathrm{H} 3 \cdots \mathrm{O} 2$ distance of $2.12(6) \AA)$ involving the amide functional group (graph set motif C(4)) [41]. Another interesting feature concerns the layered organization of the units in a non-centrosymmetric fashion. Further studies will concern the non-linear optical properties of this compound [42,43].

\subsection{Halogen Bonding Properties}

The crystallographic study of I-azo- $\mathrm{NO}_{2}$ and I-azo-NH-MMA has confirmed that the tetrafluoroiodobenzene ring is a versatile and reliable XB donor group allowing the formation of complicated architectures by self-assembly [44].

A further study aimed at highlighting the ability of the $\mathrm{XB}$ group to function in an intermolecular recognition process. Halide anions are particularly effective in the construction of robust supramolecular architectures, and several research works have reported the sensing of anions by halogen bonding $[45,46]$. Therefore, an ${ }^{19} \mathrm{~F}-\mathrm{NMR}$ spectroscopic analysis was performed to monitor the interaction of the $\mathrm{XB}$ donor azo dyes with chloride anions in solution. In practice, I-azo- $\mathrm{NO}_{2}$ and I-azo-NH-MMA were challenged with increasing quantities of tetrabutylammonium chloride (TBACl) in deuterated chloroform using bis(2,2,2-trifluoroethyl) ether as internal reference standard. The NMR titration experiments reveal an upfield shift of both $\mathrm{C}-\mathrm{F}$ signals corresponding to fluorine atoms ortho and meta to the iodine atom upon treatment with TBACl (Figure 4). The ${ }^{19} \mathrm{~F}-\mathrm{NMR}$ resonances for I-azo- $\mathrm{NO}_{2}$ and I-azo-NH-MMA exhibit marked variations with $\delta$ decreasing by ca. $-0.5 \mathrm{ppm}$ in the presence of 10 equivalents of TBACl. Note that the same trend is observed with I-azo- $\mathrm{NH}_{2}$ (Figure S2, Supplementary Materials). In these cases, this shifting behavior is attributed to formation of $\mathrm{I} \cdot \mathrm{Cl}^{-}$halogen bonded adducts in solution (Figure S8, Supplementary Materials). 
A
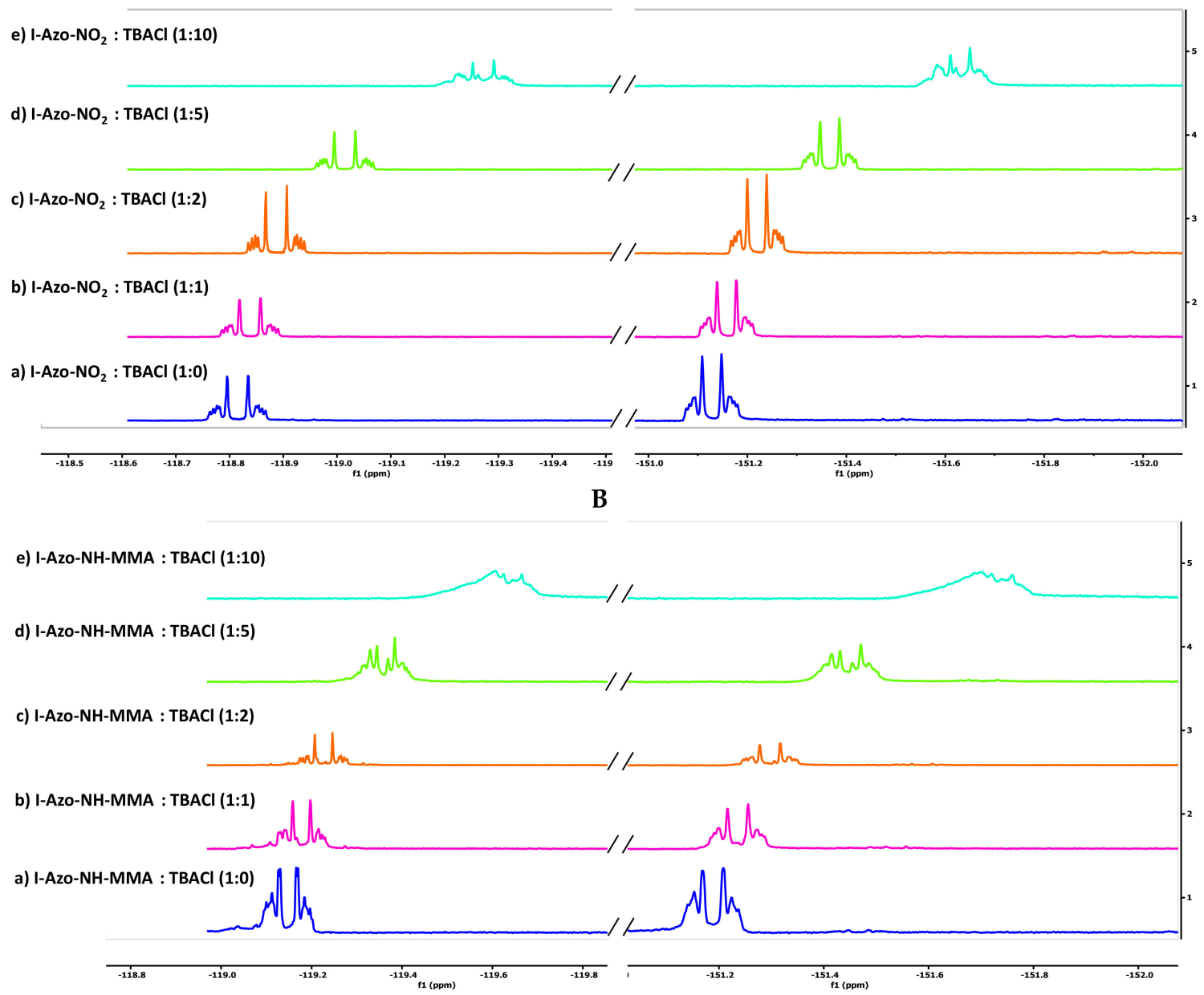

Figure 4. Stack plot of ${ }^{19} \mathrm{~F}-\mathrm{NMR}$ spectra of I-azo-NO2 and I-azo-NH-MMA $\left(\mathrm{CDCl}_{3}\right)$, at different molar ratios of I-azo$\mathrm{NO}_{2} / \mathrm{TBACl}(\mathbf{A})$ and I-azo-NH-MMA/TBACl (B). Molar ratios: (a) 1:0; (b) 1:1; (c) 1:2; (d) 1:5; (e) 1:10.

\subsection{Photo-Responsive Properties}

Subsequently, the photo-responsiveness of these compounds was investigated. For this, dichloromethane solutions of I-azo- $\mathrm{NO}_{2}$ and I-azo-NH-MMA and an acetonitrile solution of I-azo- $\mathrm{NH}_{2}$ were treated by UV light irradiation $(366 \mathrm{~nm}$ ) (Figure 5). As concerns I-azo- $\mathrm{NO}_{2}$ and I-azo-NH-MMA, the UV-Vis spectra reveal a significant decrease of the main band at $\sim 360 \mathrm{~nm}$ assigned to the $\pi \rightarrow \pi^{*}$ absorption, and a slight strengthening of $n \rightarrow \pi^{*}$ band at $\sim 460 \mathrm{~nm}$. The same trend is observed for I-azo- $\mathrm{NH}_{2}$ but the main band is slightly shifted at $389 \mathrm{~nm}$. These variations are typically observed for a conformational change of the diazobenzene unit, indicating a trans to cis isomerization. The reversible character of this phenomenon was demonstrated through a relaxation kinetic study that occurs within $8 \mathrm{~h}$ for all compounds after leaving the solutions in darkness or after irradiation with white light for 2 min (Figure 5). 
A

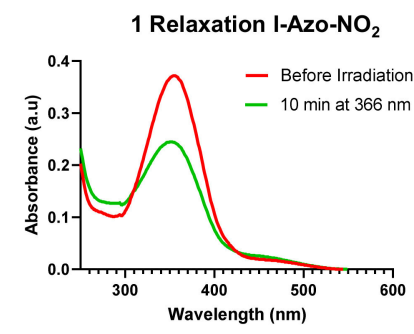

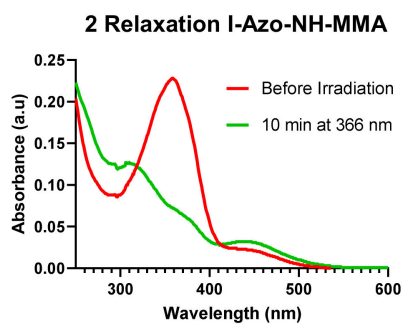

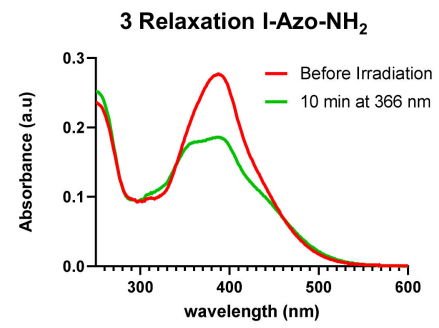

B
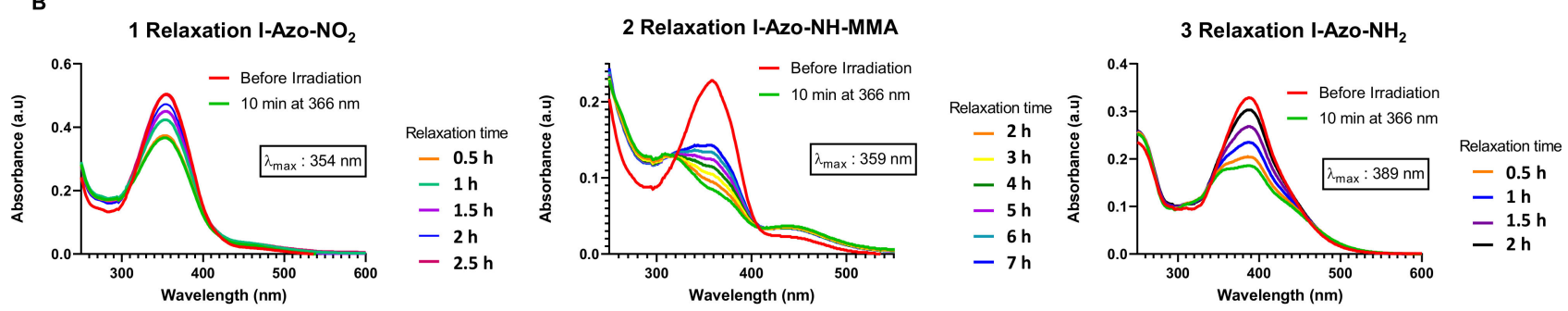

Figure 5. UV-Vis spectra for I-azo- $\mathrm{NO}_{2}$ (A1), I-azo-NH-MMA (A2) and I-azo-NH $\mathrm{NH}_{2}$ (A3) before (red) and after (green) a $10 \mathrm{~min}$ exposure to $366 \mathrm{~nm}$ light. Thermal relaxation spectra in the dark for I-azo-NO $\mathrm{NO}_{2}(\mathbf{B 1})$, I-azo-NH-MMA (B2) and I-azo-NH2 (B3).

\section{5. $p H$ Sensitivity}

4-aminoazobenzene belongs to a family of dyes that undergo protonation accompanying a pronounced color change in acidic environment [47]. In addition to the isomerization and $\mathrm{XB}$ donor properties, the $\mathrm{pH}$ sensitivity of $\mathrm{I}-\mathrm{azo}-\mathrm{NH} 2$ was demonstrated in solution. After solubilization in acetonitrile, the neutral medium reveals an orange color that turns red after addition of one drop of concentrated $\mathrm{HCl} 36 \%$ (Figure 6). Afterwards, this system exhibits a reversible color change upon addition of a few drops of sodium hydroxide. $\mathrm{I}-\mathrm{azo}-\mathrm{NH} 2$ is thereby endowed with a triple stimuli responsiveness.

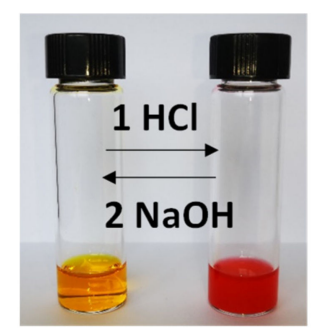

Figure 6. Acetonitrile solution of I-azo-NH2 (left) and after acidic treatment (right).

\section{Materials and Methods}

All non-aqueous reactions were run in oven-dried glassware under a positive pressure of argon or nitrogen, with exclusion of moisture from reagents and glassware using standard techniques for manipulating air-sensitive compounds. Solvents were purchased from Chemlabs (Zedelgem, Belgium) and dried using molecular sieves of $4 \AA$ or standard distillation techniques. Iodopentafluorobenzene was purchased from Fluorochem (Derbyshire, UK). Nitroaniline was purchased from Apollo scientific (Bredbury, Stockport, UK) (nitroaniline was purified by flash chromatography on silica gel before use). $\mathrm{Na}_{2} \mathrm{~S}, \mathrm{NaNO}_{2}$ and phenol were purchased from Merck (Frankfurt, Germany). Methyl methacrylate was purchased from TCI chemicals (Zwijndrecht, Belgium). Reactions were monitored by analytical thin-layer chromatography (TLC) performed on pre-coated, aluminum-backed silica gel plates. Visualization of the developed chromatogram was performed by UV absorbance at $254 \mathrm{~nm}$ or $366 \mathrm{~nm}$. Flash chromatography was performed on a $230-400$ mesh silica 
gel with the indicated solvent systems. Infrared spectra were recorded on an IRAffinity-1 Shimadzu (Duisburg, Germany) FT-IR spectrometer and are reported in reciprocal centimeters $\left(\mathrm{cm}^{-1}\right)$. Routine nuclear magnetic resonance spectra were recorded on a JEOL $400 \mathrm{MHz}$ (Zaventem, Belgium). Chemical shifts for 1H and 13C-NMR spectra are recorded in parts per million from solvent resonance as the internal standard. Data are reported as follows: chemical shift, integration, multiplicity $(\mathrm{s}=$ singlet, $\mathrm{d}=$ doublet, $\mathrm{dd}=$ double doublet, $\mathrm{t}=$ triplet, $\mathrm{q}=$ quartet, $\mathrm{m}=$ multiplet and $\mathrm{br}=$ broad), and coupling constants are in Hz. High-resolution mass spectrometry spectra were recorded on a MS QTOF-6520 Agilent (Santa Clara, CA, USA) for structure confirmation. UV Spectra were recorded on a Spectrophotometer Shimadzu (Duisburg, Germany) UV-1800 in the $250 \mathrm{~nm}-600 \mathrm{~nm}$ range for each spectrum.

\subsection{Synthetic Procedures}

4-((4-nitrophenyl)diazenyl)phenol ( $\left.\mathrm{HO}-a z o-\mathrm{NO}_{2}\right)$. This compound was prepared according to a previously reported procedure [28]. 4-Nitroaniline ( $3 \mathrm{~g}, 0.022 \mathrm{~mol})$ was added to the hydrochloric acid aqueous solution $(10 \%, 50 \mathrm{~mL})$ and was stirred until complete dissolution. Sodium nitrite $(1.95 \mathrm{~g}, 0.029 \mathrm{~mol})$ was dissolved in water $(40 \mathrm{~mL})$ and was added dropwise to the above solution within $1 \mathrm{~h}$, then stirred for another $30 \mathrm{~min}$, keeping the temperature below $0{ }^{\circ} \mathrm{C}$. Phenol $(2.66 \mathrm{~g}, 0.028 \mathrm{~mol})$ and sodium hydroxide $(1.11 \mathrm{~g}, 0.028 \mathrm{~mol})$ were dissolved in water $(40 \mathrm{~mL})$, and the mixture was added dropwise to the diazonium salt solution within $1 \mathrm{~h}$, keeping the temperature below $0{ }^{\circ} \mathrm{C}$. The reaction was completed after stirring for another $3 \mathrm{~h}$ below $2{ }^{\circ} \mathrm{C}$. After stirring at room temperature for $24 \mathrm{~h}$, an orange product was precipitated and collected by filtration to afford $\mathrm{HO}-$ azo- $\mathrm{NO}_{2}$. Yield: $96 \%$. Mp: $218-220{ }^{\circ} \mathrm{C} .{ }^{1} \mathrm{H}-\mathrm{NMR}\left(400 \mathrm{MHz}, \mathrm{CDCl}_{3}, \mathrm{ppm}\right) \delta 8.39(2 \mathrm{H}, \mathrm{d}, J=9.2 \mathrm{~Hz}), 8.00(2 \mathrm{H}, \mathrm{d}$, $J=9.2 \mathrm{~Hz}), 7.96(2 \mathrm{H}, \mathrm{d}, J=8.8 \mathrm{~Hz}), 7.00(2 \mathrm{H}, \mathrm{d}, J=8.8 \mathrm{~Hz}), 5.59(1 \mathrm{H}, \mathrm{br}) .{ }^{13} \mathrm{C}-\mathrm{NMR}(400$ $\mathrm{MHz}, \mathrm{CDCl}_{3}$, ppm) $\delta, 160.42,156.16,148.36,147.01,126.01,124.86,123.24,116.27$.

4-((4-(2,3,5,6-tetrafluoro-4-iodophenoxy) phenyl)diazenyl)nitrobenzene (I-azo- $\left.\mathrm{NO}_{2}\right)$. HOazo- $\mathrm{NO}_{2}\left(1.0 \mathrm{~g}, 1\right.$ equiv.) was dissolved in DMF $(15 \mathrm{~mL})$ at $50^{\circ} \mathrm{C}$. Potassium carbonate (1.3 equiv.) was added to the reaction mixture and vigorously stirred for $20 \mathrm{~min}$. Pentafluoroiodobenzene (1.1 equiv.) was added dropwise to the reaction mixture and the reaction was stirred for $6 \mathrm{~h}$. Upon complete conversion of $\mathrm{HO}-\mathrm{azo}-\mathrm{NO}_{2}$, the reaction was precipitated in water and the solid was washed with $n$-hexane yielding I-azo- $-\mathrm{NO}_{2}$ as a deep red solid. Furthermore, the aqueous layer was extracted with diethyl ether three times, and the organic layer was dried over anhydrous sodium sulphate $\left(\mathrm{Na}_{2} \mathrm{SO}_{4}\right)$ and concentrated to afford I-azo-NO $\mathrm{NO}_{2}$. Yield: $95 \%$. Mp: $165-168{ }^{\circ} \mathrm{C} .{ }^{1} \mathrm{H}-\mathrm{NMR}\left(400 \mathrm{MHz}, \mathrm{CDCl}_{3}, \mathrm{ppm}\right) \delta 8.37$ $(2 \mathrm{H}, \mathrm{d}, J=9.2 \mathrm{~Hz}), 8.00(4 \mathrm{H}, \mathrm{m}), 7.13(2 \mathrm{H}, \mathrm{d}, J=9.2 \mathrm{~Hz},) .{ }^{13} \mathrm{C}-\mathrm{NMR}\left(101 \mathrm{MHz}, \mathrm{CDCl}_{3}, \mathrm{ppm}\right)$ $\delta$ 159.78, 155.79, 148.94, 148.82, 125.69, 124.89, $123.53,116.26 .{ }^{19} \mathrm{~F}-\mathrm{NMR}\left(376 \mathrm{MHz}, \mathrm{CDCl}_{3}\right.$, ppm) $\delta-118.83,-151.14$. HR-MS (ESI) [M - H] ${ }^{+}$Calculated: 517.9619; Found: 517.9618 $(0.26 \mathrm{ppm})$

4-((4-aminophenyl)diazenyl)phenol (HO-azo- $\left.\mathrm{NH}_{2}\right)$. This compound was prepared according to a previously reported procedure [28]. $\mathrm{HO}-\mathrm{azo}-\mathrm{NO}_{2}$ ( $3 \mathrm{~g}$, 1 equiv., $12.35 \mathrm{mmol}$ ) is dissolved in dioxane $(50 \mathrm{~mL})$ and an aqueous solution of $\mathrm{Na}_{2} \mathrm{~S}$ ( $3.85 \mathrm{~g}, 6$ equiv., $49.4 \mathrm{mmol}$ ) is added to the reaction mixture at $70{ }^{\circ} \mathrm{C}$ in two times $\mathrm{t}=0 \mathrm{~min}$ and $\mathrm{t}=3 \mathrm{~h}$ The reaction is stirred overnight and stopped once there is no more evidence of starting material checked by TLC. Dioxane is concentrated and the crude material is extracted three times with diethyl ether, washed with an aqueous solution of sodium carbonate, dried over sodium sulphate and the organic layer is concentrated affording a red solid. The crude material was purified by column chromatography using dichloromethane as eluent to afford HO-azo- $\mathrm{NH}_{2}$. Yield: $92 \%$. Mp: $185{ }^{\circ} \mathrm{C}$ (decomposed). ${ }^{1} \mathrm{H}-\mathrm{NMR}\left(400 \mathrm{MHz}, \mathrm{CD}_{3} \mathrm{OD}\right.$, ppm) $\delta 7.68(2 \mathrm{H}, \mathrm{d}, J=8.8 \mathrm{~Hz}), 7.65(2 \mathrm{H}, \mathrm{d}, J=8.8 \mathrm{~Hz}), 6.86(2 \mathrm{H}, \mathrm{d}, J=8.8 \mathrm{~Hz}), 6.74(2 \mathrm{H}$, $\mathrm{d}, J=8.8 \mathrm{~Hz}) .{ }^{13} \mathrm{C}-\mathrm{NMR}\left(101 \mathrm{MHz}, \mathrm{CD}_{3} \mathrm{OD}, \mathrm{ppm}\right) \delta 160.66,152.53,147.75,145.86,125.48$, $124.94,116.56,115.37$.

4-((4-(2,3,5,6-tetrafluoro-4-iodophenoxy) phenyl)diazenyl)aniline (I-azo- $\left.\mathrm{NH}_{2}\right)$. HO-azo$\mathrm{NH}_{2}(2.15 \mathrm{~g}$, 1 equiv., $10.10 \mathrm{mmol})$ was dissolved in DMF $(25 \mathrm{~mL})$ at $50{ }^{\circ} \mathrm{C}$. Potassium 
carbonate ( $1.81 \mathrm{~g}$, 1.3 equiv., $13.13 \mathrm{mmol})$ was added to the reaction mixture and vigorously stirred for $20 \mathrm{~min}$. Pentafluoroiodobenzene ( $2.97 \mathrm{~g}$, 1.2 equiv., $20.2 \mathrm{mmol}$ ) was added dropwise to the reaction mixture and the reaction was stirred for $6 \mathrm{~h}$. Upon complete conversion of $\mathrm{HO}-\mathrm{azo}-\mathrm{NH}_{2}$, the reaction was precipitated in water and the solid was washed with $n$-hexane yielding $\mathrm{I}-\mathrm{azo}-\mathrm{NH}_{2}$ as an orange solid. Furthermore, the aqueous layer was extracted with diethyl ether three times, and the organic layer was dried over anhydrous $\mathrm{Na}_{2} \mathrm{SO}_{4}$ and concentrated to afford I-azo- $\mathrm{NH}_{2}$. Yield: 91\%. Mp: 165-168 ${ }^{\circ} \mathrm{C}$. ${ }^{1} \mathrm{H}-\mathrm{NMR}\left(400 \mathrm{MHz}, \mathrm{CDCl}_{3}, \mathrm{ppm}\right) \delta 7.85(2 \mathrm{H}, \mathrm{d}, J=9.2 \mathrm{~Hz}), 7.78(2 \mathrm{H}, \mathrm{d}, J=8.8 \mathrm{~Hz}), 7.06$ $(2 \mathrm{H}, \mathrm{d}, J=9.2 \mathrm{~Hz}), 6.73(2 \mathrm{H}, \mathrm{d}, J=8.8 \mathrm{~Hz}), 4.05(2 \mathrm{H}, \mathrm{br}) .{ }^{13} \mathrm{C}-\mathrm{NMR}\left(101 \mathrm{MHz}, \mathrm{CDCl}_{3}, \mathrm{ppm}\right)$ $\delta 157.98,149.72,149.52,145.58,125.20,124.22,116.07,114.77 .{ }^{19} \mathrm{~F}-\mathrm{NMR}\left(376 \mathrm{MHz}, \mathrm{CDCl}_{3}\right.$, ppm) $\delta-119.35,-151.26$. HR-MS (ESI) $[\mathrm{M}+\mathrm{H}]^{+}$Calculated: 487.9877; Found: 487.9900 (4.54 ppm)

N-(4-((4-(2,3,5,6-tetrafluoro-4-iodophenoxy)phenyl)diazenyl)phenyl)methacrylamide (I-azo$\mathrm{NH}-\mathrm{MMA})$. To a stirred solution of I-azo- $\mathrm{NH}_{2}(0.5 \mathrm{~g}, 1.03 \mathrm{mmol}, 1$ equiv.) in dichloromethane $(3 \mathrm{~mL})$ were added triethylamine $(430 \mu \mathrm{L}, 3.08 \mathrm{mmol}, 3$ equiv.) and methacryloyl chloride $\left(150 \mu \mathrm{L}, 1.54 \mathrm{mmol}, 1.5\right.$ equiv.) at $0{ }^{\circ} \mathrm{C}$. After stirring for $5 \mathrm{~min}$, the mixture was allowed to warm up to room temperature and stirred for $1 \mathrm{~h}$. Then the reaction was quenched with $\mathrm{H}_{2} \mathrm{O}$ and extracted with dichloromethane $(3 \times 15 \mathrm{~mL})$. The combined organic layers were washed with brine, dried over anhydrous $\mathrm{Na}_{2} \mathrm{SO}_{4}$, concentrated under reduced pressure and purified by column chromatography using dichloromethane as eluent to afford I-azo-NH-MMA. Yield: 87\%. Mp: 200-202 ${ }^{\circ} \mathrm{C} .{ }^{1} \mathrm{H}-\mathrm{NMR}\left(400 \mathrm{MHz}, \mathrm{CDCl}_{3}\right) \delta 7.93$ $(2 \mathrm{H}, \mathrm{d}, J=8.8 \mathrm{~Hz}), 7.929(2 \mathrm{H}, \mathrm{d}, J=9.2 \mathrm{~Hz}) 7.74(2 \mathrm{H}, \mathrm{d}, J=9.2 \mathrm{~Hz}), 7.67(\mathrm{~s}, 1 \mathrm{H}), 7.09(2 \mathrm{H}, \mathrm{d}$, $J=8.8 \mathrm{~Hz}), 5.84(1 \mathrm{H}, \mathrm{m}), 5.52(1 \mathrm{H}, \mathrm{m}), 2.09(3 \mathrm{H}, \mathrm{dd}, J=1.6 \mathrm{~Hz}, J=0.9 \mathrm{~Hz}) .{ }^{13} \mathrm{C}-\mathrm{NMR}(101$ $\left.\mathrm{MHz}_{2} \mathrm{CDCl}_{3}\right) \delta 166.66,158.72,149.07,149.02,140.96,140.58,124.83,124.24,120.45,120.10$, 116.14, 18.88. ${ }^{19} \mathrm{~F}-\mathrm{NMR}\left(376 \mathrm{MHz} \mathrm{CDCl}_{3}\right) \delta-119.17,-151.21$. HR-MS (ESI) $[\mathrm{M}+\mathrm{H}]^{+}$ Calculated: 556.0150; Found: 556.0149 (1.65 ppm)

\subsection{X-ray Crystallography}

For the structures of I-azo- $\mathrm{NO}_{2}$ and I-azo-NH-MMA, X-ray intensity data were collected at $100 \mathrm{~K}$, on a Rigaku Oxford Diffraction (Rigaku Corporation, Oxford, UK) Supernova Dual Source ( $\mathrm{Cu}$ at zero) diffractometer equipped with an Atlas CCD detector using $\omega$ scans and $\mathrm{CuK} \alpha(\lambda=1.54184 \AA)$ radiation. The images were interpreted and integrated with the program CrysAlisPro (versions 1.171.40.53 and 1.171.40.67a; Rigaku Corporation, Oxford, UK) [48]. Using Olex2, [49] the structures were solved by direct methods using the ShelXT structure solution program and refined by full-matrix least-squares on $\mathrm{F}^{2}$ using the ShelXL program package [50,51]. Non-hydrogen atoms were anisotropically refined and the hydrogen atoms in the riding mode with isotropic temperature factors fixed at 1.2 times $\mathrm{U}(\mathrm{eq})$ of the parent atoms (1.5 times for methyl groups). For I-azo-NH-MMA, the amide $\mathrm{H}$-atom was located from a difference Fourier electron density map and refined with an $\mathrm{N}-\mathrm{H}$ restrained distance of $0.88 \AA$.

\section{3. ${ }^{19}$ F-NMR Titrations}

Titrations of I-azo- $\mathrm{NO}_{2}, \mathrm{I}-\mathrm{azo}-\mathrm{NH}_{2}$ and I-azo-NH-MMA with the tetrabutylammonium chloride salt (TBACl) were monitored by ${ }^{19} \mathrm{~F}-\mathrm{NMR}$. Stock solutions of $25 \mathrm{mM}$ $(2 \mathrm{~mL})$ and $100 \mathrm{mM}(1 \mathrm{~mL})$ of the azo dyes and TBACl were prepared in $\mathrm{CDCl}_{3}$. Bis(2,2,2trifluoroethyl) ether was used as internal standard. Titration samples were prepared as follows (Table 3): 
Table 3. ${ }^{19}$ F-NMR titration of azo dyes with tetrabutylammonium chloride salt.

\begin{tabular}{ccccc}
\hline $\begin{array}{c}\text { Molar Ratio of } \\
\text { Azo-Dye:TBACl }\end{array}$ & $\begin{array}{c}\text { Volume of } \\
\text { Azo-Dye Stock } \\
\text { Solution }(\mu \mathrm{L})\end{array}$ & $\begin{array}{c}\text { Volume of } \\
\text { TBACl Stock } \\
\text { Solution }(\mu \mathrm{L})\end{array}$ & $\begin{array}{c}\text { Volume of } \\
\mathrm{CDCl}_{3}(\boldsymbol{\mu L})\end{array}$ & $\begin{array}{c}\text { Total } \\
\text { Volume }(\mu \mathrm{L})\end{array}$ \\
\hline $1: 0$ & 200 & 0 & 500 & 700 \\
\hline $1: 1$ & 200 & 50 & 450 & 700 \\
\hline $1: 2$ & 200 & 100 & 400 & 700 \\
\hline $1: 5$ & 200 & 250 & 250 & 700 \\
\hline $1: 10$ & 200 & 500 & 0 & 700 \\
\hline
\end{tabular}

\subsection{UV-Vis Analysis of Azobenzenes}

UV-visible spectroscopic studies were performed with solutions of $10 \mu \mathrm{M}$ of azobenzene derivatives in dichloromethane for I-azo- $\mathrm{NO}_{2}$ and I-azo-NH-MMA and acetonitrile for I-azo- $\mathrm{NH}_{2}$. Spectra were recorded before and after irradiation at $366 \mathrm{~nm}$ for $10 \mathrm{~min}$. The kinetics of cis to trans isomerization were determined by recording absorption spectra every $30 \mathrm{~min}$ for $8 \mathrm{~h}$ after $10 \mathrm{~min}$ of irradiation at $366 \mathrm{~nm}$.

\section{5. $p H$ Sensitivity}

$3 \mathrm{mg}$ of I-azo- $\mathrm{NH}_{2}$ were solubilized in $3 \mathrm{~mL}$ of acetonitrile. After addition of two to three drops of $\mathrm{HCl} 36 \%$, the solution turned red. Then, 2 drops of concentrated $\mathrm{NaOH}$ solution $(28 \mathrm{M})$ were added, leading to an orange solution.

\section{Conclusions}

In summary, we have reported the synthesis of new azobenzene derivatives bearing halogen bond donor groups. The X-ray analyses of I-azo- $\mathrm{NO}_{2}$ and I-azo-NH-MMA highlight supramolecular arrangements developing undulating chains due to non-covalent bonds. In I-azo- $\mathrm{NO}_{2}$, the nitro group is simultaneously engaged in orthogonal hydrogen and halogen bonds, which has been scarcely reported to date. In light of the literature, the self-complementary $\mathrm{Ar}-\mathrm{I} \cdots \mathrm{O}_{2} \mathrm{~N}-\mathrm{Ar}$ synthon can self-assemble in a head-to-tail mode, arising thus as a very appealing motif to design supramolecular architectures in a high reliable fashion (Scheme S1, Supplementary Materials). Regarding I-azo-NH-MMA, a non-centrosymmetric organization was observed thanks to uncommon $\mathrm{I} \cdots \mathrm{CH}_{2}=\mathrm{C}$ halogen bonding. A survey of the Cambridge Structural Database reveals that only four structures involve this contact. In addition to the crystallographic studies, ${ }^{19} \mathrm{~F}-\mathrm{NMR}$ spectroscopic analyses have emphasized that such compounds can be involved in intermolecular recognition processes, as proposed through $\mathrm{I} \cdots \mathrm{Cl}^{-}$halogen bonding in solution. Subsequently, the photo-responsiveness of all XB-based compounds was studied by irradiation at $366 \mathrm{~nm}$. As expected, a trans to cis isomerization was confirmed by UV-Vis analysis, this phenomenon being reversible. Finally, the synthetic intermediate $\mathrm{I}-\mathrm{azo}-\mathrm{NH}_{2}$ shows a light and $\mathrm{pH}$ responsive profile in combination with a halogen bond donor ability, with a potential application in anion sensing. Further works will aim at preparing polymeric materials using these stimuli responsive units and their application in the preparation of functional compounds.

Supplementary Materials: Figure S1: X-ray structures of HOQKAC (A), HOTZOH (B), PEQVOZ (C) and USAJIK (D) showing the $\mathrm{I} \cdots \mathrm{CH}_{2}=\mathrm{C}$ halogen bonds found in the Cambridge Structural Database (CSD version 5.42 updates, Sep 2021). Colors are as follows: grey, C; blue, N; red, oxygen; white, H; orange, S; purple, I. Figure S2: Stack plot of ${ }^{19} \mathrm{~F}-\mathrm{NMR}$ spectra of I-azo- $\mathrm{NH}_{2}\left(\mathrm{CDCl}_{3}\right)$, at different molar ratios of I-azo-NH $\mathrm{NH}_{2} / \mathrm{TBACl}$. Molar ratios: (a) 1:0; (b) 1:1; (c) 1:2; (d) 1:5; (e) 1:10. Figure S3. ${ }^{1} \mathrm{H}$ and ${ }^{13} \mathrm{C}-\mathrm{NMR}$ spectra for compound $\mathrm{OH}-\mathrm{azo}-\mathrm{NH}_{2}$. Figure $\mathrm{S} 4 .{ }^{1} \mathrm{H}$ and ${ }^{13} \mathrm{C}-\mathrm{NMR}$ spectra for compound $\mathrm{OH}$-azo- $\mathrm{NO}_{2}$. Figure S5. ${ }^{1} \mathrm{H},{ }^{19} \mathrm{~F}$ and ${ }^{13} \mathrm{C}-\mathrm{NMR}$ spectra for compound I-azo$\mathrm{NO}_{2}$. Figure S6. ${ }^{1} \mathrm{H},{ }^{19} \mathrm{~F}$ and ${ }^{13} \mathrm{C}-\mathrm{NMR}$ spectra for compound $\mathrm{I}-\mathrm{azo}-\mathrm{NH}_{2}$. Figure $\mathrm{S} 7 .{ }^{1} \mathrm{H},{ }^{19} \mathrm{~F}$ and ${ }^{13} \mathrm{C}-\mathrm{NMR}$ spectra for compound I-azo-NH-MMA. Scheme S1. Self-complementary Ar-I $\cdots \mathrm{O}_{2} \mathrm{~N}-\mathrm{Ar}$ 
synthon. Halogen and hydrogen bonds are represented in blue and red dashed lines, respectively. Figure S8. ${ }^{19} \mathrm{~F}$ NMR titration curves of I-azo-NO $\mathrm{NO}_{2}(\mathbf{A}), \mathrm{I}-\mathrm{azo}-\mathrm{NH}_{2}(\mathbf{B})$ and I-azo-NH-MMA (C) with tetrabutylammonium chloride. Molar ratios (azo dyes/TBACl): 1:0; 1:1; 1:2; 1:5; 1:10.

Author Contributions: Conceptualization, F.M.; methodology, F.M., P.F. and S.K.; software, K.V.H.; validation, F.M., P.F., M.G. and S.K.; formal analysis, F.M., P.F., S.K., M.G. and K.V.H.; investigation, F.M., P.F. and S.K.; resources, F.M.; data curation, P.F., S.K. and K.V.H.; writing—original draft preparation, F.M., P.F. and S.K.; writing-review and editing, F.M.; supervision, F.M.; project administration, F.M.; funding acquisition, F.M. All authors have read and agreed to the published version of the manuscript.

Funding: S.K. and F.M. thank ULB for the financial support (PDR 35275398). K.V.H. thanks the Research Foundation-Flanders (FWO) (projects AUGE/11/029 and G099319N) for funding.

Data Availability Statement: The data presented in this study are available in the Supplementary Materials.

Acknowledgments: We are also grateful to the analytical platform of the faculty of pharmacy (ULB) for mass spectroscopy analyses.

Conflicts of Interest: The authors declare that they have no conflict of interest.

\section{References}

1. Zhang, X.; Chen, L.; Lim, K.H.; Gonuguntla, S.; Lim, K.W.; Pranantyo, D.; Yong, W.P.; Yam, W.J.T.; Low, Z.; Teo, W.J.; et al. The Pathway to Intelligence Using Stimuli-Responsive Materials as Building Blocks for Constructing Smart and Functional Systems. Adv. Mater. 2019, 31, 1804540. [CrossRef] [PubMed]

2. McCune, J.A.; Mommer, S.; Parkins, C.C.; Scherman, O.A. Design Principles for Aqueous Interactive Materials: Lessons from Small Molecules and Stimuli-Responsive Systems. Adv. Mater. 2020, 32, 1906890. [CrossRef] [PubMed]

3. Mrinalini, M.; Prasanthkumar, S. Recent Advances on Stimuli-Responsive Smart Materials and Their Applications. Chempluschem 2019, 84, 1103-1121. [CrossRef] [PubMed]

4. Rahim, M.A.; Jan, N.; Khan, S.; Shah, H.; Madni, A.; Khan, A.; Jabar, A.; Khan, S.; Elhissi, A.; Hussain, Z.; et al. Recent Advancements in Stimuli Responsive Drug Delivery Platforms for Active and Passive Cancer Targeting. Cancers 2021, 13, 670. [CrossRef]

5. Hu, L.; Shu, T.; Wan, Y.; Fang, C.; Gao, F.; Serpe, M.J. Recent Advances in Stimuli-Responsive Polymers for Sensing and Actuation. Mol. Syst. Des. Eng. 2021, 6, 108-121. [CrossRef]

6. Gu, X.; Wang, J.; Liu, X.; Zhao, D.; Wang, Y.; Gao, H.; Wu, G. Temperature-Responsive Drug Delivery Systems Based on Polyaspartamides with Isopropylamine Pendant Groups. Soft Matter 2013, 9, 7267-7273. [CrossRef]

7. Suedee, R.; Jantarat, C.; Lindner, W.; Viernstein, H.; Songkro, S.; Srichana, T. Development of a PH-Responsive Drug Delivery System for Enantioselective-Controlled Delivery of Racemic Drugs. J. Control. Release 2010, 142, 122-131. [CrossRef]

8. Maggini, L.; Raquez, J.-M.; Marega, R.; Jensen Ahrens, J.; Pineux, F.; Meyer, F.; Dubois, P.; Bonifazi, D. Magnetic Poly(Vinylpyridine)-Coated Carbon Nanotubes: An Efficient Supramolecular Tool for Wastewater Purification. ChemSusChem 2013, 6, 367-373. [CrossRef]

9. Wang, Y.; Liu, D.; Zheng, Q.; Zhao, Q.; Zhang, H.; Ma, Y.; Fallon, J.K.; Fu, Q.; Haynes, M.T.; Lin, G.; et al. Disulfide Bond Bridge Insertion Turns Hydrophobic Anticancer Prodrugs into Self-Assembled Nanomedicines. Nano Lett. 2014, 14, $5577-5583$. [CrossRef]

10. Zhou, Y.-N.; Li, J.-J.; Zhang, Q.; Luo, Z.-H. Light-Responsive Smart Surface with Controllable Wettability and Excellent Stability. Langmuir 2014, 30, 12236-12242. [CrossRef]

11. Tao, Y.; Chan, H.F.; Shi, B.; Li, M.; Leong, K.W. Light: A Magical Tool for Controlled Drug Delivery. Adv. Funct. Mater. 2020, 30, 1-28. [CrossRef]

12. Giles, L.W.; Faul, C.F.J.; Tabor, R.F. Azobenzene Isomerization in Condensed Matter: Lessons for the Design of Efficient LightResponsive Soft-Matter Systems. Mater. Adv. 2021, 2, 4152-4164. [CrossRef]

13. Merino, E. Synthesis of Azobenzenes: The Coloured Pieces of Molecular Materials. Chem. Soc. Rev. 2011, 40, 3835-3853. [CrossRef]

14. Bandara, H.M.D.; Burdette, S.C. Photoisomerization in Different Classes of Azobenzene. Chem. Soc. Rev. 2012, 41, 1809-1825. [CrossRef]

15. Dong, M.; Babalhavaeji, A.; Samanta, S.; Beharry, A.A.; Woolley, G.A. Red-Shifting Azobenzene Photoswitches for in Vivo Use. Acc. Chem. Res. 2015, 48, 2662-2670. [CrossRef]

16. Cavallo, G.; Metrangolo, P.; Milani, R.; Pilati, T.; Priimagi, A.; Resnati, G.; Terraneo, G. The Halogen Bond. Chem. Rev. 2016, 116, 2478-2601. [CrossRef]

17. Gilday, L.C.; Robinson, S.W.; Barendt, T.A.; Langton, M.J.; Mullaney, B.R.; Beer, P.D. Halogen Bonding in Supramolecular Chemistry. Chem. Rev. 2015, 115, 7118-7195. [CrossRef] 
18. Bulfield, D.; Huber, S.M. Halogen Bonding in Organic Synthesis and Organocatalysis. Chem. A Eur. J. 2016, 22, 14434-14450. [CrossRef]

19. Wilcken, R.; Zimmermann, M.O.; Lange, A.; Joerger, A.C.; Boeckler, F.M. Principles and Applications of Halogen Bonding in Medicinal Chemistry and Chemical Biology. J. Med. Chem. 2013, 56, 1363-1388. [CrossRef]

20. Berger, G.; Frangville, P.; Meyer, F. Halogen Bonding for Molecular Recognition: New Developments in Materials and Biological Sciences. Chem. Commun. 2020, 56, 4970-4981. [CrossRef]

21. Priimagi, A.; Cavallo, G.; Forni, A.; Gorynsztejn-Leben, M.; Kaivola, M.; Metrangolo, P.; Milani, R.; Shishido, A.; Pilati, T.; Resnati, G.; et al. Halogen Bonding versus Hydrogen Bonding in Driving Self-Assembly and Performance of Light-Responsive Supramolecular Polymers. Adv. Funct. Mater. 2012, 22, 2572-2579. [CrossRef]

22. Saccone, M.; Dichiarante, V.; Forni, A.; Goulet-Hanssens, A.; Cavallo, G.; Vapaavuori, J.; Terraneo, G.; Barrett, C.J.; Resnati, G.; Metrangolo, P.; et al. Supramolecular Hierarchy among Halogen and Hydrogen Bond Donors in Light-Induced Surface Patterning. J. Mater. Chem. C 2015, 3, 759-768. [CrossRef]

23. Bushuyev, O.S.; Corkery, T.C.; Barrett, C.J.; Friščić, T. Photo-Mechanical Azobenzene Cocrystals and in Situ X-Ray Diffraction Monitoring of Their Optically-Induced Crystal-to-Crystal Isomerisation. Chem. Sci. 2014, 5, 3158-3164. [CrossRef]

24. Tong, X.; Qiu, Y.; Zhao, X.; Xiong, B.; Liao, R.; Peng, H.; Liao, Y.; Xie, X. Visible Light-Triggered Gel-to-Sol Transition in Halogen-Bond-Based Supramolecules. Soft Matter 2019, 15, 6411-6417. [CrossRef]

25. Saccone, M.; Cavallo, G.; Metrangolo, P.; Resnati, G.; Priimagi, A. Halogen-Bonded Photoresponsive Materials. Top. Curr. Chem. 2015, 359, 147-166. [CrossRef]

26. Berger, G.; Soubhye, J.; Meyer, F. Halogen Bonding in Polymer Science: From Crystal Engineering to Functional Supramolecular Polymers and Materials. Polym. Chem. 2015, 6, 3559-3580. [CrossRef]

27. Chikh Alard, I.; Soubhye, J.; Berger, G.; Gelbcke, M.; Spassov, S.; Amighi, K.; Goole, J.; Meyer, F. Triple-Stimuli Responsive Polymers with Fine Tuneable Magnetic Responses. Polym. Chem. 2017, 8, 2450-2456. [CrossRef]

28. Zhou, D.; Wang, Y.; Jia, J.; Yu, W.; Qu, B.; Li, X.; Sun, X. H-Bonding and Charging Mediated Aggregation and Emission for Fluorescence Turn-on Detection of Hydrazine Hydrate. Chem. Commun. 2015, 51, 10656-10659. [CrossRef]

29. Tothadi, S.; Desiraju, G.R. Designing Ternary Cocrystals with Hydrogen Bonds and Halogen Bonds. Chem. Commun. 2013, 49, 7791-7793. [CrossRef]

30. Batsanov, S.S. Van Der Waals Radii of Elements. Inorg. Chem. 2001, 37, 1031-1046. [CrossRef]

31. Voth, A.R.; Khuu, P.; Oishi, K.; Ho, P.S. Halogen Bonds as Orthogonal Molecular Interactions to Hydrogen Bonds. Nat. Chem. 2009, 1, 74-79. [CrossRef] [PubMed]

32. Vasylyeva, V.; Nayak, S.K.; Terraneo, G.; Cavallo, G.; Metrangolo, P.; Resnati, G. Orthogonal Halogen and Hydrogen Bonds Involving a Peptide Bond Model. CrystEngComm 2014, 16, 8102-8105. [CrossRef] [PubMed]

33. Van Terwingen, S.; Brüx, D.; Wang, R.; Englert, U. Hydrogen-Bonded and Halogen-Bonded Orthogonal Interactions for the Chloride Anion of a Pyrazolium Salt. Molecules 2021, 26, 3982. [CrossRef] [PubMed]

34. Thalladi, V.R.; Goud, B.S.; Hoy, V.J.; Allen, F.H.; Howard, J.A.K.; Desiraju, G.R. Supramolecular Synthons in Crystal Engineering Structure Simplification, Synthon Robustness and Supramolecular Retrosynthesis. Chem. Commun. 1996, 401-402. [CrossRef]

35. Lu, S.; Ng, S.V.H.; Lovato, K.; Ong, J.Y.; Poh, S.B.; Ng, X.Q.; Kürti, L.; Zhao, Y. Practical Access to Axially Chiral Sulfonamides and Biaryl Amino Phenols via Organocatalytic Atroposelective N-Alkylation. Nat. Commun. 2019, 10, 3061. [CrossRef]

36. Shao, W.H.; Chen, B.Y.; Cheng, X.R.; Yuan, H.; Chen, H.; Chang, W.L.; Ye, J.; Lin, S.; Sun, Q.Y.; Zhang, W.D. Synthesis and Evaluation of New $\alpha$-Methylene- $\gamma$-Lactone Carbamates with NO Production Inhibitory Effects in Lipopolysaccharide-Induced RAW 264.7 Macrophages. Eur. J. Med. Chem. 2015, 93, 274-280. [CrossRef]

37. Röse, P.; Emge, S.; Yoshida, J.I.; Hilt, G. Electrochemical Selenium- and Iodonium-Initiated Cyclisation of Hydroxy-Functionalised 1,4-Dienes. Beilstein J. Org. Chem. 2015, 11, 174-183. [CrossRef]

38. Ren, X.; Tang, L.; Shen, C.; Li, H.; Wang, P.; Dong, K. Enantioselective Hydroesterificative Cyclization of 1,6-Enynes to Chiral $\gamma$-Lactams Bearing a Quaternary Carbon Stereocenter. Org. Lett. 2021, 23, 3561-3566. [CrossRef]

39. Berger, G.; Soubhye, J.; van der Lee, A.; Vande Velde, C.; Wintjens, R.; Dubois, P.; Clément, S.; Meyer, F. Interplay between Halogen Bonding and Lone Pair- $\pi$ Interactions: A Computational and Crystal Packing Study. Chempluschem 2014, 79, 552-558. [CrossRef]

40. Berger, G.; Robeyns, K.; Soubhye, J.; Wintjens, R.; Meyer, F. Halogen Bonding in a Multi-Connected 1,2,2-Triiodo-Alkene Involving Geminal and/or Vicinal Iodines: A Crystallographic and DFT Study. CrystEngComm 2016, 18, 683-690. [CrossRef]

41. Etter, M.C. Encoding and Decoding Hydrogen-Bond Patterns of Organic Compounds. Acc. Chem. Res. 1990, 23, 120-126. [CrossRef]

42. Cariati, E.; Forni, A.; Biella, S.; Metrangolo, P.; Meyer, F.; Resnati, G.; Righetto, S.; Tordin, E.; Ugo, R. Tuning Second-Order NLO Responses through Halogen Bonding. Chem. Commun. 2007, 2590-2592. [CrossRef]

43. Virkki, M.; Tuominen, O.; Forni, A.; Saccone, M.; Metrangolo, P.; Resnati, G.; Kauranen, M.; Priimagi, A. Halogen Bonding Enhances Nonlinear Optical Response in Poled Supramolecular Polymers. J. Mater. Chem. C 2015, 3, 3003-3006. [CrossRef]

44. Baldrighi, M.; Metrangolo, P.; Meyer, F.; Pilati, T.; Proserpio, D.; Resnati, G.; Terraneo, G. Halogen-Bonded and Interpenetrated Networks through the Self-Assembly of Diiodoperfluoroarene and Tetrapyridyl Tectons. J. Fluor. Chem. 2010, 131, 1218-1224. [CrossRef]

45. Kumar, V.; Pilati, T.; Terraneo, G.; Meyer, F.; Metrangolo, P.; Resnati, G. Halogen Bonded Borromean Networks by Design: Topology Invariance and Metric Tuning in a Library of Multi-Component Systems. Chem. Sci. 2017, 8, 1801-1810. [CrossRef] 
46. Lim, J.Y.C.; Beer, P.D. Sigma-Hole Interactions in Anion Recognition. Chem 2018, 4, 731-783. [CrossRef]

47. Machida, K.; Kim, B.-K.; Saito, Y.; Igarashi, K.; Uno, T. Resonance Raman Spectra of Acid-Base Indicators. I. p-Aminoazobenzene Derivatives. Bull. Chem. Soc. Jpn. 1974, 47, 78-83. [CrossRef]

48. Rigaku Oxford Diffraction. CrysAlisPro Software Systems; Rigaku Corporation: Oxford, UK, 2019.

49. Dolomanov, O.V.; Bourhis, L.J.; Gildea, R.J.; Howard, J.A.K.; Puschmann, H. OLEX2: A Complete Structure Solution, Refinement and Analysis Program. J. Appl. Crystallogr. 2009, 42, 339-341. [CrossRef]

50. Sheldrick, G.M. SHELXT - Integrated Space-Group and Crystal-Structure Determination. Acta Crystallogr. Sect. A Found. Crystallogr. 2015, 71, 3-8. [CrossRef]

51. Sheldrick, G.M. Crystal Structure Refinement with SHELXL. Acta Crystallogr. Sect. C Struct. Chem. 2015, 71, 3-8. [CrossRef] 